\title{
Association of the interleukin-18 -137 C/G, -607 A/C polymorphisms with type 1 diabetes: A meta-analysis
}

\author{
JING LI, SONG WU, MING-RUI WANG, TING-TING WANG, BAI-KUN LI and JI-MIN ZHU \\ Department of Public Health and General Medicine, School of Integrated Traditional and Western Medicine, \\ Anhui University of Chinese Medicine, Hefei, Anhui 230038, P.R. China
}

Received May 30, 2013; Accepted September 16, 2013

DOI: $10.3892 / \mathrm{br} .2013 .186$

\begin{abstract}
Published data on the association between interleukin (IL)-18 gene polymorphisms (-137 C/G, -607 A/C) and type 1 diabetes (T1D) risk are inconclusive. To obtain a more precise estimation of the association between the IL-18 gene polymorphisms and T1D, a meta-analysis was performed. A total of 11 studies including 5,945 cases and 6,404 controls were included in the analysis of the association between $-137 \mathrm{C} / \mathrm{G}$ and T1D risk. No significant association between $-137 \mathrm{C} / \mathrm{G}$ and T1D risk was observed in the total population [C vs. G: odds ratio $(\mathrm{OR})=1.02,95 \%$ confidence interval $(\mathrm{CI})=0.87-1.20 ; \mathrm{CC}+\mathrm{CG}$ vs. $\mathrm{GG}: \mathrm{OR}=1.05,95 \% \mathrm{CI}=0.87-1.25$; $\mathrm{CC}$ vs. $\mathrm{CG}+\mathrm{GG}$ : $\mathrm{OR}=0.96,95 \% \mathrm{CI}=0.68-1.36]$. No significant association was identified in the stratified analysis for all the genetic models in the European population. Concerning -607 A/C, 10 studies involving 3,048 patients and 3,377 controls were included in this meta-analysis. When all the studies were pooled, the results showed no evidence for a significant association between IL-18 -607 A/C polymorphism and T1D risk (A vs. $\mathrm{C}$ : $\mathrm{OR}=0.93,95 \% \mathrm{CI}=0.81-1.06$; $\mathrm{AA}+\mathrm{AC}$ vs. $\mathrm{CC}$ : $\mathrm{OR}=0.99,95 \% \mathrm{CI}=0.89-1.10$; $\mathrm{AA}$ vs. $\mathrm{AC}+\mathrm{CC}$ : $\mathrm{OR}=0.81,95 \% \mathrm{CI}=0.60-1.09)$. In addition, similar results were obtained in the subgroup analysis based on ethnicity. In summary, the present meta-analysis suggests a lack of association between the two polymorphisms $(-137 \mathrm{C} / \mathrm{G},-607 \mathrm{~A} / \mathrm{C})$ in the IL-18 gene and T1D. Due to the limitation of the number of the studies, the conclusions drawn should be considered with caution. Larger scale primary studies are required to evaluate the association between IL-18 gene polymorphisms and T1D.
\end{abstract}

Correspondence to: Dr Ji-Min Zhu, Department of Public Health and General Medicine, School of Integrated Traditional and Western Medicine, Anhui University of Chinese Medicine, 103 Meishan Road, Hefei, Anhui 230038, P.R. China

E-mail: zhjmcdc@126.com

Abbreviations: IL-18, interleukin-18; T1D, type 1 diabetes; OR, odds ratio; CI, confidence interval; HWE, Hardy-Weinberg equilibrium

Key words: interleukin-18, genetic polymorphisms, type 1 diabetes, meta-analysis

\section{Introduction}

Type 1 diabetes (T1D) is a chronic autoimmune disease characterized by the T-cell-mediated destruction of pancreatic $\beta$ cells and subsequent dependence on exogenous insulin (1). T1D affects millions of individuals worldwide and its incidence is on the increase, particularly in young children $(2,3)$. The etiology of T1D is multifactorial and complex, with genetic and environmental factors playing a role in its pathogenesis (4-6). Human leukocyte antigen (HLA) genes are considered to greatly affect the development of T1D. Genetic determinants such as polymorphisms in the HLA region are crucial, accounting for $40-50 \%$ of the inheritable diabetes risk (7). In addition, there is evidence that proinflammatory cytokines contribute to the genetic susceptibility to T1D, such as interleukin (IL)-1, IL-2, IL-12, IL-18 and interferon (IFN)- $\gamma$ (8).

IL-18, a member of the IL-1 superfamily, is a proinflammatory cytokine produced by activated monocytes/macrophages. Through a concerted action with IL-12, IL-18 promotes the development of Th1 lymphocyte response by induction of IFN- $\gamma$ production. IL-18 also modulates the activity of NK cells, increases tumor necrosis factor (TNF)- $\alpha$ and IL-1. Evidence suggests that IL-18 is involved in the regulation of the innate and adaptive immune response and may have a pathogenic role in T1D. Nicoletti et al (9) reported that serum IL-18 levels were elevated in the subclinical stage of T1D in first-degree relatives of T1D patients. Rothe et al $(10,11)$ found that increased IL-18 mRNA production by macrophages followed by increased IFN- $\gamma$ levels was associated with an active stage of autoimmune diabetes in non-obese diabetic (NOD) mice. Moreover, it has been found that in the animal model of autoimmune diabetes a short prophylactic treatment with IL-18 inhibitors resulted in significant protection against development of this disease (12).

The IL-18 gene is located on chromosome 11q22.2-q22.3, and comprises six exons and five introns (13). Of the IL-18 gene polymorphisms identified, the genetic association between single nucleotide polymorphisms (SNPs) at positions -137, -607 in IL-18 gene promoter and T1D were widely evaluated. However, the results were inconsistent. Meta-analysis is a statistical procedure for combining the results of several studies to produce a single estimate of the major effect with enhanced precision. Thus, in order to examine the relationship between IL-18 gene polymorphisms (-137 C/G, -607 A/C) and susceptibility to T1D, a meta-analysis was performed. 
Table I. The characteristics of studies included in the meta-analysis.

\begin{tabular}{|c|c|c|c|c|c|c|c|c|c|}
\hline \multirow[b]{2}{*}{ Polymorphisms } & \multirow[b]{2}{*}{ Author (year) } & \multirow[b]{2}{*}{ Ethnic group } & \multicolumn{2}{|c|}{ Nos. } & \multicolumn{2}{|c|}{$\begin{array}{c}\text { Allele } \\
\text { frequency }(\%)^{\mathrm{a}}\end{array}$} & \multicolumn{2}{|c|}{$\begin{array}{l}\text { HWE for } \\
\text { controls }\end{array}$} & \multirow[b]{2}{*}{ Refs. } \\
\hline & & & T1D & Control & T1D & Control & $\chi^{2}$ & $\mathrm{P}$-value & \\
\hline \multirow[t]{11}{*}{$-137 \mathrm{C} / \mathrm{G}$} & Kretowski et al (2002) & Poland (E) & 201 & 194 & 37.6 & 27.3 & 9.400 & $<0.01$ & $(23)$ \\
\hline & Ide et al (2004) & Japan (A) & 116 & 114 & 12.1 & 11.4 & 0.230 & 0.63 & $(22)$ \\
\hline & Novota et al (2005) & Czech Republic (E) & 49 & 139 & 34.7 & 28.8 & 1.080 & 0.30 & $(26)$ \\
\hline & Martin et al (2005) & UK (E) & 433 & 426 & 25.8 & 28.1 & 0.013 & 0.91 & (24) \\
\hline & Boraska et al (2006) & Croatia (E) & 134 & 132 & 28.7 & 28.8 & 0.001 & 0.98 & $(20)$ \\
\hline & Szeszko et al (2006) & UK (E) & 4,323 & 4,610 & 26.4 & 26.6 & 1.418 & 0.23 & (27) \\
\hline & Mojtahedi et al (2006) & $\operatorname{Iran}(\mathrm{A})$ & 112 & 194 & 30.8 & 24.0 & 0.003 & 0.95 & $(25)$ \\
\hline & Dong et al (2007) & China (A) & 118 & 150 & 14.0 & 10.7 & 0.004 & 0.95 & $(21)$ \\
\hline & Altinova et al (2010) & Turkey (E) & 91 & 87 & 26.4 & 25.9 & 0.010 & 0.92 & (19) \\
\hline & Hadžija et al (2013) & Croatia $(\mathrm{E})$ & 187 & 236 & 29.7 & 33.1 & 0.274 & 0.60 & (18) \\
\hline & Tavares et al (2013) & Brazil (S) & 181 & 122 & 28.5 & 43.9 & 0.320 & 0.57 & (17) \\
\hline \multirow[t]{10}{*}{$-607 \mathrm{~A} / \mathrm{C}$} & Kretowski et al (2002) & Poland (E) & 201 & 194 & 32.1 & 34.0 & 13.421 & $<0.01$ & $(23)$ \\
\hline & Ide et al (2004) & Japan (A) & 116 & 114 & 46.6 & 55.3 & 3.328 & 0.07 & $(22)$ \\
\hline & Novota et al (2005) & Czech Republic (E) & 49 & 139 & 56.1 & 42.4 & 1.116 & 0.29 & (26) \\
\hline & Martin et al (2005) & UK (E) & 433 & 426 & 36.5 & 40.8 & 0.172 & 0.68 & (24) \\
\hline & Szeszko et al (2006) & UK (E) & 1,560 & 1,715 & 39.2 & 38.1 & 0.462 & 0.50 & (27) \\
\hline & Mojtahedi et al (2006) & $\operatorname{Iran}(\mathrm{A})$ & 112 & 194 & 44.6 & 41.2 & 0.795 & 0.37 & $(25)$ \\
\hline & Dong et al (2007) & China (A) & 118 & 150 & 41.2 & 53.0 & 0.138 & 0.71 & $(21)$ \\
\hline & Altinova et al (2010) & Turkey (E) & 91 & 87 & 35.7 & 35.6 & 2.027 & 0.15 & (19) \\
\hline & Hadžija et al (2013) & Croatia (E) & 187 & 236 & 42.5 & 44.9 & 1.471 & 0.23 & (18) \\
\hline & Tavares et al (2013) & Brazil & 181 & 122 & 42.5 & 46.3 & 0.180 & 0.67 & (17) \\
\hline
\end{tabular}

${ }^{\mathrm{a}}$ Frequency of the $\mathrm{C}$ allele for $-137 \mathrm{C} / \mathrm{G}$; frequency of the A allele for $-607 \mathrm{~A} / \mathrm{C}$. E, European; A, Asian; S, South American; T1D, type 1 diabetes; HWE, Hardy-Weinberg equilibrium.

\section{Materials and methods}

Identification of eligible studies and data extraction. Studies examining the association of IL-18 -137 C/G (rs187238), -607 A/C (rs1946518) polymorphisms with T1D were fully considered and carefully selected. The literature was searched using the following electronic databases: Medline, PubMed, China National Knowledge Infrastructure (CNKI) and CBM. The search was based on the combinations of 'type 1 diabetes', 'polymorphisms' or 'variant', 'interleukin-18' or 'IL-18'. No language restrictions were applied. We only recruited complete published studies, and not any data from conference abstracts or meetings. A study was included when the following criteria were met: i) it was published up to April 2013; ii) it was a case-control study; iii) it provided sufficient data for estimating the odds ratio (OR). When more than one study of the same patient population was included in several publications, only the most recent or complete study was used in this meta-analysis. Furthermore, two investigators independently searched the electronic database and extracted available information from each study, including first author's name, year of publication, country where the trial was conducted, ethnicity, number of cases and controls, as well as data available on allele and genotype frequency of IL-18 $-137 \mathrm{C} / \mathrm{G}$, $-607 \mathrm{~A} / \mathrm{C}$ polymorphisms.
Evaluation of statistical associations. Allele frequencies of IL-18 -137 C/G, -607 A/C polymorphisms in each of the studies were determined using the allele counting method. The strength of association between these variants and T1D was achieved by calculating OR with $95 \%$ confidence interval (CI). We assessed the within- and between- study variation or heterogeneity by means of the Cochran's Q-statistic (14). $\mathrm{P}>0.10$ for the Q-test indicated a lack of heterogeneity among studies, and then the fixed-effect model was used. Otherwise, results of the random-effect model were selected. The effect of heterogeneity was quantified by using the measurement method, $\mathrm{I}^{2}=100 \% \mathrm{x}(\mathrm{Q}-\mathrm{df}) / \mathrm{Q}(15)$. The $\mathrm{I}^{2}$ measures the degree of inconsistency in the studies by calculating the percentage of total variation across studies as being due to heterogeneity rather than chance. $\mathrm{I}^{2}$ values of 25,50 , and $75 \%$ were nominally considered low, moderate and high estimates.

Evaluation of publication bias. Publication bias was investigated by using a funnel plot, in which the standard error of $\log (\mathrm{OR})$ of each study was plotted against its OR. The degree of asymmetry was achieved using the method of Egger's linear regression test (16). The significance of the intercept was determined by the t-test suggested by Egger. $\mathrm{P}<0.05$ was considered representative of statistically significant publication bias. 


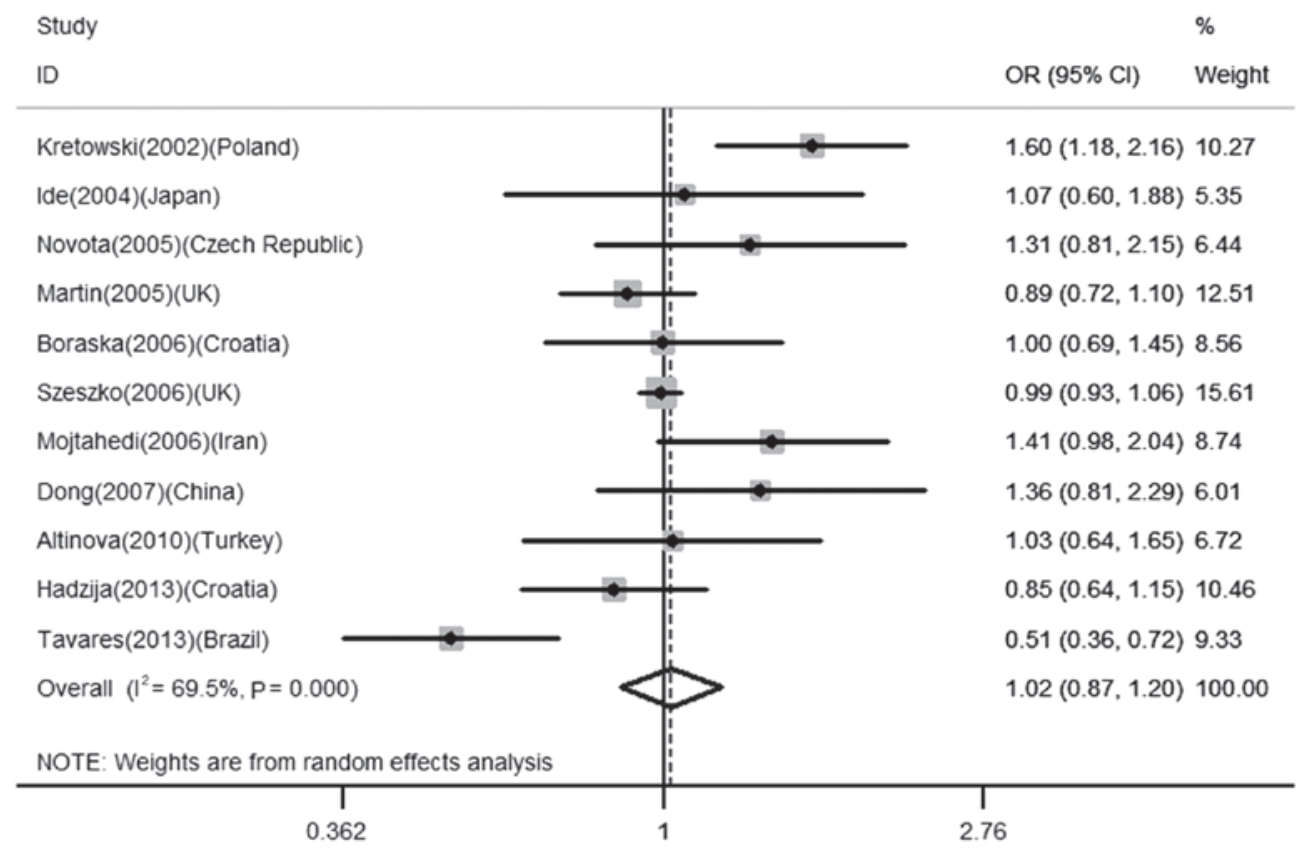

Figure 1. Odss ratio and 95\% confidence interval for individual studies and pooled data for the association of IL-18 -137 C vs. G allele in the total population.

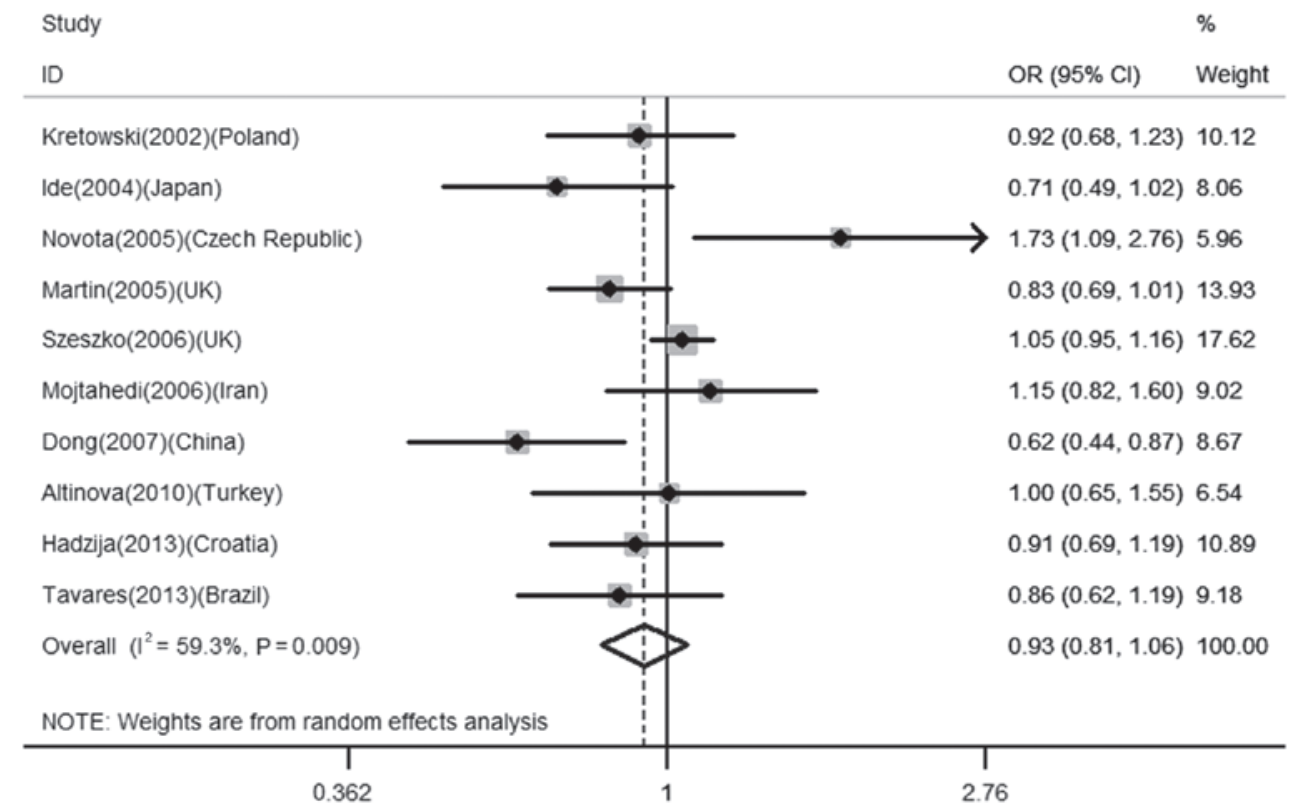

Figure 2. Odss ratio and 95\% confidence interval for individual studies and pooled data for the association of IL-18 -607 A vs. C allele in the total population.

Statistical analysis. All the statistical analyses were carried out using the software package Stata Version 10.0 (Stata Corporation, College Station, TX, USA), using two-sided $\mathrm{P}$-values. $\mathrm{P}<0.05$ was considered to indicate a statistically significant difference.

\section{Results}

Characteristics of the articles in our meta-analysis. The search words yielded 26 relevant studies. Following careful review, 15 of the 26 articles were excluded ( 8 were conducted to examine other IL-18 polymorphisms or other diseases; 4 were reviews; 2 were duplicated data publications; and 1 was letter). Therefore, a total of 11 case-control studies were considered in this meta-analysis (17-27). Table I presents the studies identified and their main characteristics. Of the 11 studies, 7 studies were of Europeans, 3 of Asians and 1 study of South Americans. The results of the Hardy-Weinberg equilibrium (HWE) test for the distribution of the genotype in the control population are also shown in Table I. One study was not in HWE in the eligible studies (23).

Association between IL-18-137 C/G polymorphism and the risk for T1D. A total of 11 studies comprising 5,945 cases and 


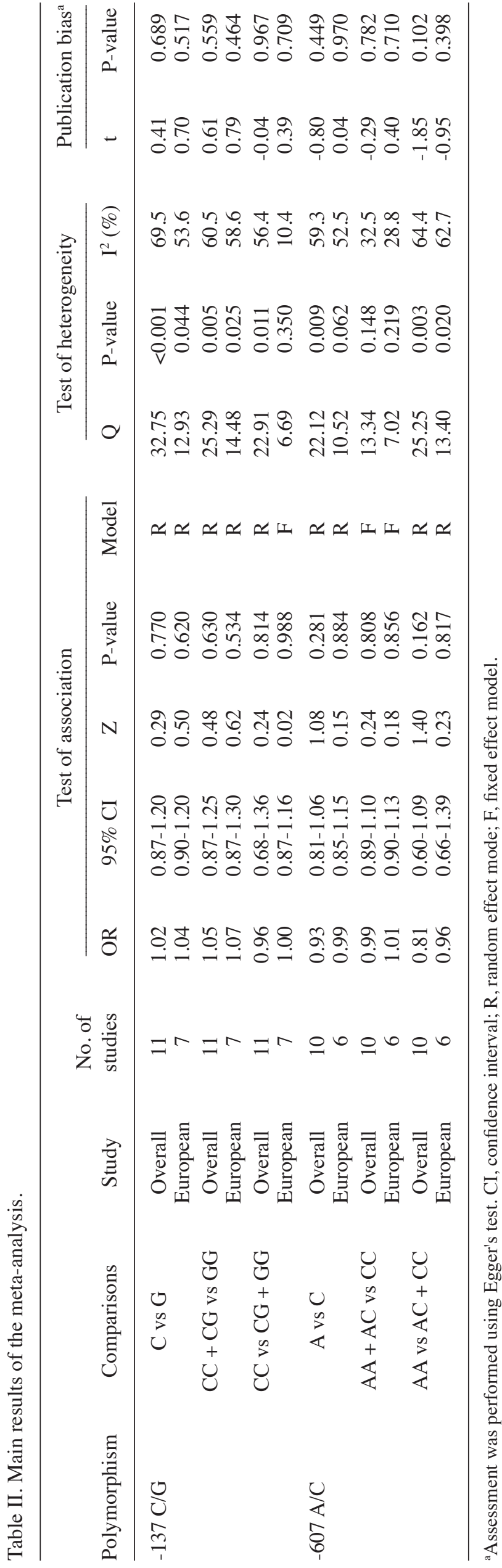

6,404 controls were included in order to analyze the association between $-137 \mathrm{C} / \mathrm{G}$ and T1D risk. Overall, no significant relationship was observed in the total population (for $\mathrm{C}$ vs. G: $\mathrm{OR}=1.02,95 \% \mathrm{CI}=0.87-1.20, \mathrm{P}=0.770 ; \mathrm{CC}+\mathrm{CG}$ vs. $\mathrm{GG}$ : $\mathrm{OR}=1.05,95 \% \mathrm{CI}=0.87-1.25, \mathrm{P}=0.630 ; \mathrm{CC}$ vs. $\mathrm{CG}+\mathrm{GG}$ : $\mathrm{OR}=0.96,95 \% \mathrm{CI}=0.68-1.36, \mathrm{P}=0.814)$, as shown in Table II and Fig. 1. Similarly, in the subsequent stratified analysis, no significant association was identified between the IL-18 $-137 \mathrm{C} / \mathrm{G}$ polymorphism and T1D in the European population (for $\mathrm{C}$ vs. $\mathrm{G}$ : $\mathrm{OR}=1.04,95 \% \mathrm{CI}=0.90-1.20, \mathrm{P}=0.620 ; \mathrm{CC}+\mathrm{CG}$ vs. GG: $\mathrm{OR}=1.07,95 \% \mathrm{CI}=0.87-1.30, \mathrm{P}=0.534 ; \mathrm{CC}$ vs. $\mathrm{CG}+$ GG: $\mathrm{OR}=1.00,95 \% \mathrm{CI}=0.87-1.16, \mathrm{P}=0.988)$.

Association between - $607 \mathrm{~A} / \mathrm{C}$ polymorphism and the risk for $T 1 D$. The association between $-607 \mathrm{~A} / \mathrm{C}$ polymorphism and T1D was investigated in 10 studies with a total of 3,048 cases and 3,377 controls. No significant association was found between this polymorphism and T1D in any of the genetic models in the total population (for A vs. $\mathrm{C}$ : $\mathrm{OR}=0.93,95 \% \mathrm{CI}=0.81-1.06$, $\mathrm{P}=0.281 ; \mathrm{AA}+\mathrm{AC}$ vs. $\mathrm{CC}: \mathrm{OR}=0.99,95 \% \mathrm{CI}=0.89-1.10$, $\mathrm{P}=0.808$; AA vs. $\mathrm{AC}+\mathrm{CC}: \mathrm{OR}=0.81,95 \% \mathrm{CI}=0.60-1.09$, $\mathrm{P}=0.162$ ), as shown in Table II and Fig. 2. While stratified by ethnicity with European populations, similar results were obtained (for A vs. C: $\mathrm{OR}=0.99,95 \% \mathrm{CI}=0.85-1.15, \mathrm{P}=0.884$; $\mathrm{AA}+\mathrm{AC}$ vs. $\mathrm{CC}: \mathrm{OR}=1.01,95 \% \mathrm{CI}=0.90-1.13, \mathrm{P}=0.856$; $\mathrm{AA}$ vs. $\mathrm{AC}+\mathrm{CC}: \mathrm{OR}=0.96,95 \% \mathrm{CI}=0.66-1.39, \mathrm{P}=0.817)$.

Evaluation of publication bias. Egger's test was performed to estimate the publication bias of literature. The results of Egger's linear regression test are listed in Table II. No publication bias was identified for any of the comparisons $(\mathrm{P}>0.05)$.

\section{Discussion}

Significant familial aggregation, convincing demonstrations of multiple genetic linkages and its associations indicate a genetic component as a risk factor in the pathogenesis of T1D (28). Candidate gene studies have identified numerous susceptibility genes for T1D, such as MHC, PTPN22 and CTLA4 (29).

IL-18 is a strong candidate for T1D as it has been shown to have a central role in autoimmunity in experimental models $(30,31)$. Several variants in the IL-18 gene have been identified, with the $-137 \mathrm{C} / \mathrm{G}$ and $-607 \mathrm{~A} / \mathrm{C}$ variants in the promoter region having been the most extensively examined in epidemiologic studies. A change at position -137 from $\mathrm{G}$ to $\mathrm{C}$ alters the H4TF-1 nuclear factor binding site and a change from $\mathrm{C}$ to $\mathrm{A}$ at position -607 disrupts a potential cAMP-responsive element-binding protein binding site. Cloning and gene expression analysis showed that IL-18 -137C/G and -607A/C polymorphisms were suggested to cause a difference in transcription factor binding and have an impact on IL-18 gene activity (32).

Since the first study by Kretowski et al (23) revealed a significant correlation between IL-18 (-137 C/G, -607 A/C) gene polymorphisms and T1D risk in a Polish polulation, numerous independent investigators have undertaken to replicate this association. However, the results are conflicting. The present meta-analysis of 11 eligible studies suggested that IL-18 $-137 \mathrm{C} / \mathrm{G}$ and $-607 \mathrm{~A} / \mathrm{C}$ polymorphisms did not contribute to the development of T1D in the total population. In the subgroup 
analysis concerning ethnicity, similar results were identified in all the genetic models in the European population.

The reasons that the same polymorphism plays a different role in different ethnic populations or across different studies may arise from many factors. Firstly, this contradiction might be due to exposure to different environmental factors. It is generally accepted that environmental factors may influence the penetrance of diabetes susceptibility genes (33). Exposure to a wide range of environmental microbes in early life may play a role in the modulation of the immune system, thus preventing the development of T1D (34). Secondly, deviations from HWE might contribute to the inconsistency. Testing for deviations from $\mathrm{HWE}$ is an important quality control step in population genetic studies. According to the Polish population, genotype frequencies for IL-18 $-137 \mathrm{C} / \mathrm{G}$ and $-607 \mathrm{~A} / \mathrm{C}$ polymorphisms in controls slightly deviated from HWE $(\mathrm{P}<0.05)$, which may increase the chances of obtaining false-positive results. Therefore conclusions of those authors must be interpreted with caution. Thirdly, linkage disequilibrium (LD) is relatively strong across IL-18, which may distort the results observed (35). Ide et al (22) found that a higher promoter activity of haplotype $-137 \mathrm{G} /-607 \mathrm{C}$ of the IL-18 gene might increase the expression of IL-18, resulting in upregulation of the IFN- $\gamma$-producing T-cells. It is reported that the two loci (-137 C/G, -607 A/C) were in LD (19,24). Lastly, clinical heterogeneity might also explain the discrepancy. The potential contribution of differences in patient populations (e.g., age and years from onset, as well as disease severity) might lead to different results. In the study by Martin et al (24), the age at diagnosis of cases was under 15 years, whereas in the Polish and Japanese studies the age at diagnosis was under 30 years.

The present study has some limitations that should be considered. First, publication bias, heterogeneity, and confounding factors may have distorted the meta-analysis. Second, all of the studies were performed in European-, Asian- and South American-descent populations. Future studies are needed in other ethnic populations due to possible ethnic difference of the IL-18 -137 C/G and -607 A/C polymorphisms.

In conclusion, the combined results of independent association studies by meta-analysis showed that IL-18 -137 C/G and $-607 \mathrm{~A} / \mathrm{C}$ polymorphisms may not be risk factors for T1D. Prospective studies with larger patient cohorts and relevant confounding risk factors, such as age, ethnicity and life style, are required to examine the possible effects of IL-18 polymorphisms on T1D to confirm our conclusion.

\section{Acknowledgements}

This study was financed by the Doctoral Scientific Research Foundation of Anhui University of Chinese Medicine (grant no. 2013RC002).

\section{References}

1. Nokoff NJ, Rewers M and Cree Green M: The interplay of autoimmunity and insulin resistance in type 1 diabetes. Discov Med 13: 115-122, 2012.

2. Tooley JE, Waldron-Lynch F and Herold KC: New and future immunomodulatory therapy in type 1 diabetes. Trends Mol Med 18: 173-181, 2012.

3. Daneman D: Type 1 diabetes. Lancet 367: 847-858, 2006.
4. Redondo MJ and Eisenbarth GS: Genetic control of autoimmunity in Type I diabetes and associated disorders. Diabetologia 45: 605-622, 2002

5. Gan MJ, Albanese-O'Neill A and Haller MJ: Type 1 diabetes: current concepts in epidemiology, pathophysiology, clinical care, and research. Curr Probl Pediatr Adolesc Health Care 42: 269-291, 2012.

6. Knip M: Pathogenesis of type 1 diabetes: implications for incidence trends. Horm Res Paediatr 76: 57-64, 2011.

7. Risch N: Assessing the role of HLA-linked and unlinked determinants of disease. Am J Hum Genet 40: 1-14, 1987.

8. Rabinovitch A: An update on cytokines in the pathogenesis of insulin-dependent diabetes mellitus. Diabetes Metab Rev 14: 129-151, 1998.

9. Nicoletti F, Conget I, Di Marco R, et al: Serum levels of the interferon-gamma-inducing cytokine interleukin-18 are increased in individuals at high risk of developing type I diabetes. Diabetologia 44: 309-311, 2001.

10. Rothe H, Ito Y and Kolb H: Disease resistant, NOD-related strains reveal checkpoints of immunoregulation in the pancreas. J Mol Med (Berl) 79: 190-197, 2001.

11. Rothe H, Jenkins NA, Copeland NG and Kolb H: Active stage of autoimmune diabetes is associated with the expression of a novel cytokine, IGIF, which is located near Idd2. J Clin Invest 99: 469-474, 1997.

12. Zaccone P, Phillips J, Conget I, Cooke A and Nicoletti F: IL-18 binding protein fusion construct delays the development of diabetes in adoptive transfer and cyclophosphamide-induced diabetes in NOD mouse. Clin Immunol 115: 74-79, 2005.

13. Kruse S, Kuehr J, Moseler M, et al: Polymorphisms in the IL 18 gene are associated with specific sensitization to common allergens and allergic rhinitis. J Allergy Clin Immunol 111: $117-122,2003$.

14. Cochran WG: The combination of estimates from different experiments. Biometrics 10: 101-129, 1954.

15. Higgins JP and Thompson SG: Quantifying heterogeneity in a meta-analysis. Stat Med 21: 1539-1558, 2002.

16. Egger M, Smith GD, Schneider M and Minder C: Bias in meta-analysis detected by a simple, graphical test. BMJ 315: 629-634, 1997.

17. Tavares NA, Santos MM, Moura R, Araújo J, Guimarães R, Crovella S and Brandão L: Interleukin 18 (IL18) gene promoter polymorphisms are associated with type 1 diabetes mellitus in Brazilian patients. Cytokine 62: 286-289, 2013.

18. Hadžija MP, Korolija M, Jemin N, et al: Polymorphisms in the IL-18 and IL-12B genes and their association with the clinical outcome in Croatian patients with Type 1 diabetes. Gene 512: 477-481, 2013.

19. Altinova AE, Engin D, Akbay E, et al: Association of polymorphisms in the IL-18 and IL-12 genes with susceptibility to Type 1 diabetes in Turkish patients. J Endocrinol Invest 33: 451-454, 2010.

20. Boraska V, Terzić J, Skrabić V, et al: NeuroD1 gene and interleukin-18 gene polymorphisms in type 1 diabetes in Dalmatian population of Southern Croatia. Croat Med J 47: 571-578, 2006.

21. Dong GP, Yu ZS, Liang L, Zou CC, Fu JF and Wang CL: IL-18 gene promoter $-137 \mathrm{C} / \mathrm{G}$ and $-607 \mathrm{C} / \mathrm{A}$ polymorphisms in Chinese Han children with type 1 diabetes mellitus. Int J Immunogenet 34: 75-79, 2007.

22. Ide A, Kawasaki E, Abiru N, et al: Association between IL-18 gene promoter polymorphisms and CTLA-4 gene 49A/G polymorphism in Japanese patients with type 1 diabetes. J Autoimmun 22: 73-78, 2004

23. Kretowski A, Mironczuk K, Karpinska A, et al: Interleukin-18 promoter polymorphisms in type 1 diabetes. Diabetes 51: 3347-3349, 2002.

24. Martin RJ, Savage DA, Carson DJ, Maxwell AP and Patterson CC: Interleukin 18 promoter polymorphisms are not strongly associated with type I diabetes in a UK population. Genes Immun 6: 171-174, 2005.

25. Mojtahedi Z, Naeimi S, Farjadian S, Omrani GR and Ghaderi A: Association of IL-18 promoter polymorphisms with predisposition to Type 1 diabetes. Diabet Med 23: 235-239, 2006.

26. Novota P, Kolostova K, Pinterova D, et al: Interleukin IL-18 gene promoter polymorphisms in adult patients with type 1 diabetes mellitus and latent autoimmune diabetes in adults. Immunol Lett 96: 247-251, 2005.

27. Szeszko JS, Howson JM, Cooper JD, et al: Analysis of polymorphisms of the interleukin-18 gene in type 1 diabetes and Hardy-Weinberg equilibrium testing. Diabetes 55: 559-562, 2006. 
28. Noble JA and Erlich HA: Genetics of type 1 diabetes. Cold Spring Harb Perspect Med 2: a007732, 2012.

29. Bradfield JP, Qu HQ, Wang K, et al: A genome-wide meta-analysis of six type 1 diabetes cohorts identifies multiple associated loci. PloS Genet 7: e1002293, 2011.

30. Frigerio S, Hollander GA and Zumsteg U: Functional IL-18 is produced by primary pancreatic mouse islets and NIT-1 beta cells and participates in the progression towards destructive insulitis. Horm Res 57: 94-104, 2002.

31. Lukic ML, Mensah-Brown E, Wei X, Shahin A and Liew FY: Lack of the mediators of innate immunity attenuate the development of autoimmune diabetes in mice. J Autoimmun 21: 239-246, 2003

32. Giedraitis V, He B, Huang WX and Hillert J: Cloning and mutation analysis of the human IL-18 promoter: a possible role of polymorphisms in expression regulation. J Neuroimmunol 112: 146-152, 2001.
33. Yoon JW and Jun HS: Role of viruses in the pathogenesis of type 1 diabetes mellitus. In: Diabetes Mellitus. LeRoith D, Taylor SI, Olefsky JM (eds.). 2nd edition. Lippincott Williams and Wilkins, New York, pp575-589, 2004.

34. McKinney PA, Okasha M, Parslow RC, et al: Early social mixing and childhood Type 1 diabetes mellitus: a case-control study in Yorkshire, UK. Diabet Med 17: 236-242, 2000.

35. Thompson SR and Humphries SE: Interleukin-18 genetics and inflammatory disease susceptibility. Genes Immun 8: 91-99, 2007. 